\title{
OUTCOME OF PATIENTS ADMITTED TO THE CCU (CRITICAL CARE UNIT) OF A TERTIARY CARE HOSPITAL WITH ACUTE EXACERBATION OF COPD AND RESPIRATORY FAILURE
}

\author{
Vaidyanathan Ramarathnam ${ }^{1}$, Arunkumar Bangarpet Venkataramanappa ${ }^{2}$ \\ ${ }^{1}$ Consultant Anaesthesiologist and Intensivist, Cauvery Hospital, Mysore. \\ ${ }^{2}$ Consultant Anaesthesiologist and Intensivist, Apollo Hospitals, Mysore.
}

\section{ABSTRACT}

\begin{abstract}
AIM
To study the outcome and predictors affecting the mortality in COPD patients with acute exacerbation and respiratory failure following pharmacotherapy, non-invasive ventilation and invasive ventilation.
\end{abstract}

\section{MATERIAL AND METHODS}

Forty patients with acute exacerbation of COPD admitted to the CCU for one year period were studied. Baseline clinical assessment, investigations, APACHE II, APACHE III and OSF scorings were done.

\section{RESULTS}

Out of 40 patients 24 responded to pharmacotherapy, of these 2 patients died due to other causes. Five patients were initiated on non-invasive ventilation of which 2 patient's required invasive ventilation. Remaining 11 patients required invasive ventilation on admission, of these 7 patients died. Mortality was 43.75\%. Multivariate analysis was done and APACHE II and Alveolar-arterial oxygen gradient $(\mathrm{A}-\mathrm{a}) \mathrm{DO}_{2}$ were independent predictors of mortality.

\section{CONCLUSION}

Although significantly high mortality was seen in mechanically ventilated patients (43.75\%), the overall mortality in this study was $22.5 \%$ and hence it can be concluded that the results of aggressive treatment of acute respiratory failure in COPD patients is favourable.

\section{KEYWORDS}

COPD, Mechanical Ventilation, APACHEII Score.

HOW TO CITE THIS ARTICLE: Ramarathnam V, Venkataramanappa AB. "Outcome of patients admitted to the CCU (Critical Care Unit) of a Tertiary Care Hospital with acute exacerbation of COPD and respiratory failure.” Journal of Evolution of Medical and Dental Sciences 2015; Vol. 4, Issue 105, December 31; Page: 16984-16987, DOI: 10.14260/jemds/2015/2565

\section{INTRODUCTION}

COPD is characterized by chronic irreversible airway obstruction leading to gradual, progressive decline of lung function punctuated by repeated episodes of exacerbations requiring hospitalization. In the United States, COPD accounts for about 14 million outpatient visits annually. In the United Kingdom, it is estimated that $1.5 \%$ of the population has COPD. Some studies report that $3-6 \%$ of AECOPD (Acute Exacerbations of COPD) patients require hospitalization and the mortality ranges from 3 to $10 \%$ during these admissions. This rate is much higher in the Intensive Care Unit (ICU) setting and approaches $30 \%$ in patients older than 65 years. ${ }^{1}$

Many such patients respond to conservative pharmacotherapy, while some patients require ventilatory support. The incidence of patients requiring mechanical ventilation ranges from 9.8-67.6\% in different studies. ${ }^{2}$ Patients requiring prolonged mechanical ventilation are candidates for potential weaning failure and high mortality. Mortality rates for patients requiring ventilator support range from $20 \%$ to $60 \%{ }^{2,3,4}$ Earlier studies have shown advanced age..$^{2,3,4}$ associated comorbid illness. ${ }^{3,4,5}$ and APACHE II.5,6,7 scores to be independent predictors of in-hospital mortality.

Financial or Other, Competing Interest: None.

Submission 13-12-2015, Peer Review 14-12-2015,

Acceptance 26-12-2015, Published 29-12-2015.

Corresponding Author:

Vaidyanathan Ramarathnam,

Department of Anesthesiology and Critical Care,

Cauvery Heart and Speciality Hospital,

Bannur Road,

Mysore-570011.

E-mail: vaidyadr78@gmail.com

DOI:10.14260/jemds/2015/2565
These data may be a valuable aid to the clinicians as well as to the patients and their relatives in predicting the outcome and decisions with regard to the initiation of mechanical ventilation.

The present study was carried out to evaluate the outcome of COPD patients and possible predictors of inhospital mortality.

\section{MATERIALS AND METHODS}

Forty patients with acute exacerbation of COPD admitted to the CCU (Critical Care Unit) for a period of one year were included in this study. Depending on the severity of exacerbation, these patients received either pharmacotherapy, Non-Invasive Ventilation (NIV) or invasive ventilation. Baseline clinical assessment, investigations, APACHE II, APACHE III and OSF (Organ System Failure) scorings were done on all patients. Other variables which were evaluated were age, Alveolar-arterial oxygen gradient (A-a) $\mathrm{DO}_{2}$ and the duration of mechanical ventilation.

\section{STATISTICAL ANALYSIS}

SPSS for Windows Version 12 was used for analysis. Parameters significant on univariate analysis $(\mathrm{P}<0.05)$ were identified as potential predictors of mortality and were further evaluated using multivariate logistic regression analysis with the clinical outcome as the dependent variable.

\section{RESULTS}

The majority of the patients in the study group were males (M: $F=77.5: 22.5$ ) and the mean age being $60+/-10$ as shown in Tables 1 and 2 . 


\begin{tabular}{|c|c|c|}
\hline Distribution & Number & Percentage \\
\hline Total no. of Patients & 40 & -- \\
\hline Male & 31 & 77.5 \\
\hline Female & 09 & 22.5 \\
\hline \multicolumn{2}{|c|}{ Table 1: Distribution of patients according to sex } \\
\hline
\end{tabular}

\begin{tabular}{|c|c|}
\hline Age Group & No. of Patients \\
\hline $30-40$ & 01 \\
\hline $40-50$ & 01 \\
\hline $50-60$ & 03 \\
\hline $60-70$ & 12 \\
\hline $70-80$ & 12 \\
\hline $80-90$ & 11 \\
\hline \multicolumn{2}{|c|}{ Total Table 2: Distribution of } \\
\hline \multicolumn{2}{|c|}{ patients according to age groups } \\
\hline
\end{tabular}

Out of these 40 patients, 24 patients responded favourably to pharmacotherapy. Two patients in this group died due to unrelated causes, one patient had acute myocardial infarction and other due to hypovolemic shock following severe haemoptysis. Mortality in this group was $8.33 \%$.

Of the remaining 16 patients, 5 were initiated on noninvasive ventilation. Of which, 2 required invasive ventilation and they recovered. No mortality was seen in these patients.
Remaining 11 patients required invasive ventilation on admission. Out of these 11 patients 7 expired. Overall, mortality for mechanically ventilated patients was $43.75 \%$ and those requiring invasive ventilation on admission was $63.63 \%$ as shown in Table 3 .

\begin{tabular}{|l|c|c|c|}
\hline \multicolumn{1}{|c|}{ Mode of Therapy } & $\begin{array}{c}\text { No. of } \\
\text { Patients }\end{array}$ & Deaths & Mortality \\
\hline Total No. of Patients & 40 & 09 & $22.5 \%$ \\
\hline $\begin{array}{l}\text { 1) On } \\
\text { pharmacotherapy }\end{array}$ & 24 & 02 & $8.33 \% *$ \\
\hline $\begin{array}{l}\text { 2) On Ventilatory } \\
\text { Support }\end{array}$ & 16 & 07 & $43.75 \%$ \\
\hline a) NIV & 03 & 00 & - \\
\hline b) NIV $\rightarrow$ IV & 02 & 00 & - \\
\hline c) IV - on admission & 11 & 7 & 63.63 \\
\hline \multicolumn{2}{|c|}{ Table 3: Mortality in patients with COPD } \\
\hline
\end{tabular}

* UNRELATED CAUSES

The variables which were entered into the univariate analysis were age, duration of mechanical ventilation, Alveolar-arterial oxygen gradient (A-a) $\mathrm{DO}_{2}$, OSF score, APACHE II and APACHE III scores. (A-a) $\mathrm{DO}_{2}$, APACHE II and OSF scores were found to predict mortality as shown in Table 4.

\begin{tabular}{|c|c|c|c|c|}
\hline Variable & Overall Mean & Alive Mean (SD) & Died Mean (SD) & 'P' value \\
\hline Age (years) & 70.31 & $71.11(10.56)$ & $69.28(13.06)$ & 0.761 \\
\hline Duration of ventilation (days) & 4.43 & $3.88(2.84)$ & $5.14(6.71)$ & 0.619 \\
\hline (A-a) DO 2 & 324.34 & $245.43(118.47)$ & $425.95(203.66)$ & 0.043 \\
\hline OSF & 2.31 & $1.88(0.78)$ & $2.85(0.37)$ & 0.010 \\
\hline APACHE II & 22.75 & $20.55(5.74)$ & $25.57(1.27)$ & 0.041 \\
\hline APACHE III & 62.06 & $56.88(14.69)$ & $68.71(19.07)$ & 0.182 \\
\hline \multicolumn{4}{|l}{ Table 4: Univariate analysis-variables compared using 't' Test } \\
\hline
\end{tabular}

These 3 variables (A-a) $\mathrm{DO}_{2}$, OSF score and APACHE II scores were further evaluated with logistic regression analysis (Table 5). APACHE II $(\mathrm{p}=0.03)$ and $(\mathrm{A}-\mathrm{a}) \mathrm{DO}_{2}(\mathrm{p}=0.010)$ were found to be independent predictors of mortality.

\begin{tabular}{|c|c|c|c|}
\hline Variable & Odds Ratio & $\mathbf{9 5 \%}$ CI & 'P' Value \\
\hline APACHE $\mathrm{II}$ & 0.986 & $0.963-1.009$ & 0.010 \\
\hline$(\mathrm{A}-\mathrm{a}) \mathrm{DO}_{2}$ & 0.636 & $0.332-1.22$ & 0.003 \\
\hline \multicolumn{4}{|c|}{ Table 5: Logistic regression analysis } \\
\hline
\end{tabular}

OSF with a p value of 0.0270 was not found to be an independent predictor.

\section{DISCUSSION}

Acute exacerbation of COPD represents a major cause of hospital admissions in USA. ${ }^{8}$ and majority of the industrialized and developing countries. Acute episodes of respiratory failure in these patients account for $5-10 \%$ of emergency admissions to the hospital. ${ }^{9}$ The estimated median values of prevalence rates of COPD in India is $5 \%$ for males and $2.7 \%$ for females. ${ }^{10}$ Non-surgical admissions with COPD accounted for about $2.9 \%$ of all ICU admissions in a large study involving 129,647 admissions to 128 ICUs across Britain for a period of 6 years. ${ }^{11}$

In this study, acute exacerbation of COPD accounted for 4.64\% of all CCU (Critical Care Unit) admissions.

In this study all patients received medical therapy with inhaled bronchodilators (Ipratropium and Salbutamol), intravenous (IV) corticosteroids and appropriate antibiotics. The favourable response to pharmacotherapy in this study was $55 \%$, which is comparable to the $46 \%$ response rate (64 patients out of 138) reported in the study of Hoo and Hakiman. ${ }^{12}$
Wherever indicated NIV was used as the initial strategy. NIV was delivered through standard BiPAP. Failure rate in this study was $40 \%$. Brochard et al. ${ }^{13}$ used BiPAP for their patients and reported a failure rate of $30 \%$. Afeesa et al. ${ }^{7}$ reported a failure rate of $46 \%$ for their patients following NIV trial. Other studies reported failure rates from $10-30 \%$ with BiPAP and pressure support modes using both nasal and facial masks with a significant proportion of them being late failures in patients who might have responded to NIV favourably initially.9,14,15,16

Mortality in patients requiring invasive ventilation is high. The mortality rate in our study for patients requiring invasive ventilation is $53.8 \%$, which is comparable to the mortality of $52.9 \%$ reported by Uegun et al. ${ }^{4}$ However, Epstein et al. ${ }^{17}$ reported a mortality of $28 \%$ in patients requiring invasive ventilation. In another study by Raurich et al. ${ }^{6}$ the mortality was $25.7 \%$.

Age of the patients with COPD has been found to be of prognostic value by some investigators. ${ }^{2,3,4}$ In a study by $\mathrm{Ai}-$ peng et al. ${ }^{5}$ older age was identified as a risk factor associated with mortality. Raurich et al. ${ }^{6}$ and Groenwegan et al. ${ }^{18}$ have also mentioned increased age as an independent predictor of mortality in their studies. However, in the present study age was not a predictor of mortality. Epstein and Nevins. ${ }^{17}$ have reported the need for mechanical ventilation for greater than 72 hours as an independent predictor of outcome. However, in this study duration of mechanical ventilation was not significantly associated with mortality. 
The average duration of mechanical ventilation in this study was 105 hours or about 4.4 days.

In the present study OSF score $(\mathrm{p}=0.010)$, APACHE II score $(p=0.041)$ and Alveolar-arterial oxygen gradient $(A-a)$ $\mathrm{DO}_{2}(\mathrm{p}=0.043)$ were significantly associated with mortality in univariate analysis. However, logistic regression analysis showed only the APACHE II score $(\mathrm{p}=0.003)$ (OR-0.986; 95\%CI-0.963-1.009) and Alveolar-arterial oxygen gradient (Aa) $\mathrm{DO}_{2} \quad(\mathrm{p}=0.001) \quad(\mathrm{OR}-0.636 ; 95 \% \mathrm{CI}-0.332-1.22)$ to be independent predictors of mortality. OSF score was not an independent predictor in the present study. However, Afeesa B, Morales IJ and others. ${ }^{7}$ have reported the organ failures to be an independent predictor of mortality in their study.

APACHE II score was found to be an independent predictor of mortality in many earlier studies. $4,5,7,17,18,19$ and the same has been noted in this study.

In our study the Alveolar-arterial oxygen gradient (A-a) $\mathrm{DO}_{2}$ was found to be an independent predictor of mortality. Similar results have been reported earlier by Hsu, Wann et al. ${ }^{20}$ in patients with respiratory failure due to various causes in a medical ICU and by Senef.et al. ${ }^{21}$ who found (A-a) $\mathrm{DO}_{2}$ to be more strongly associated with 180 day mortality rates $(22 \%$ of explanatory power) than in-hospital mortality rates ( $4 \%$ of explanatory power) in patients admitted to ICU with acute exacerbation of COPD. In contrast, Sudarshanam et al. ${ }^{22}$ found (A-a) $\mathrm{DO}_{2}$ to be significantly associated with mortality on univariate analysis but was not an independent predictor on logistic regression analysis in a study comprising patients with respiratory failure due to all causes including COPD.

In a large study, Martin J Wildman and others. ${ }^{11}$ comprising 129,647 patients across 128 CCUs in Britain found 11 factors on multivariate analysis (Age, presence of severe respiratory failure, length of stay in hospital, CPR within 24 hours of admission, intubation status in the first 24 hours in $\mathrm{CCU}, \mathrm{pH}$, arterial oxygen tension/fractional inspired oxygen gradient $\left\{\mathrm{PaO}_{2} / \mathrm{FiO}_{2}\right\}$, albumin, cardiovascular organ failure, neurological and renal organ failure) to be independent predictors of in-hospital mortality.

Similarly in a large meta-analysis comprising 37 studies which included a total of 189,772 study subjects with risk of death ranging from $3.6 \%$ for studies considering short-term mortality, $31.0 \%$ for long-term mortality (Upto $2 \mathrm{yr}$ after hospitalization) and $29.0 \%$ for studies that considered solely Intensive Care Unit (ICU)-admitted study subjects, twelve prognostic factors (Age, male sex, low BMI (Body Mass Index), cardiac failure, chronic renal failure, confusion, long-term oxygen therapy, lower limb edema, Global Initiative for Chronic Lung Disease criteria stage 4, cor pulmonale, acidemia, and elevated plasma troponin level were significantly associated with increased short-term mortality. Nine prognostic factors (Age, low body mass index, cardiac failure, diabetes mellitus, ischemic heart disease, malignancy, FEV1, long-term oxygen therapy, and $\mathrm{PaO}_{2}$ on admission) were significantly associated with long-term mortality. Three factors (Age, low Glasgow Coma Scale score, and $\mathrm{pH}$ ) were significantly associated with increased risk of mortality in ICUadmitted study subjects. ${ }^{23}$

Age, duration of ventilation, OSF, APACHE II, APACHE III and $(\mathrm{A}-\mathrm{a}) \mathrm{DO}_{2}$ were the variables taken into consideration in the present study of 40 patients. APACHE II and (A-a) DO2 were the only two factors that were independent predictors of mortality unlike the large studies quoted above.

\section{CONCLUSION}

In conclusion, it can be said that the response to various modalities of the treatment in acute exacerbation of COPD is favourable. Although, a high mortality of $43.75 \%$ was seen in mechanically ventilated patients. The overall mortality in this study was $22.5 \%$.
APACHE II score and Alveolar-arterial oxygen gradient (A-a) D02 were found to be independent predictors of mortality. Consistently, APACHE II score has been found to be an independent predictor of mortality as has been seen in many earlier studies and the same has been seen in this study.

Unlike APACHE II score, OSF score and (A-a) $\mathrm{DO}_{2}$ as indicators of mortality has not been consistent, as seen from earlier studies. In this study $(\mathrm{A}-\mathrm{a}) \mathrm{DO}_{2}$ was found to be an independent predictor of mortality. The alveolar arterial oxygen difference (A-a) $\mathrm{DO}_{2}$ on admission helps in estimating the amount of shunt fraction or inadequate gas exchange at the level of alveolo-capillary membrane thereby indirectly reflecting the severity of parenchymal damage in COPD. Thus baseline assessment of this parameter may directly predict mortality independent of other factors. APACHE II is one of the most popular and consistently used ICU scoring systems worldwide. An APACHE II score of more than 24 consistently predicts poor outcome independent of the disease and the same has been noted in this study in patients admitted with acute exacerbation of COPD.

Though numerous other scoring systems specific to lung diseases and COPD like CURB 65, CRB 65.24 BAP-65.25 or the relatively recent CAUDA $70 .^{3}$ scoring systems have evolved and has been evaluated in the recent past, none of them have the universal acceptance except for CURB 65 scoring system which was again primarily developed for community acquired pneumonia. ${ }^{26}$ In addition, APACHE II score does always gives the clinician the familiarity and ease of use at the bedside level on admission and within 24 hours. Evaluation of these data not only helps in predicting the outcome and mortality in these patients, but also aids physicians, patients and their relatives in decision making with regards to the initiation of mechanical ventilation considered as the decision point. ${ }^{19,28}$ For reasons of resource utilization and patient counseling, it definitely makes sense to identify variables that may help guide decision making at that point. $27,28,29$

\section{ACKNOWLEDGEMENTS}

The authors gratefully wish to acknowledge the help rendered by Dr. Sheela Seshagiri Rao, Prof. and HOD, Dept. of Anaesthesiology and Critical Care for her constant mentoring role during the conduct of this study, analysis of results and preparation of the manuscript.

\section{LIMITATIONS}

None of our patients had PFTs performed before hospital admissions. Depending on the clinical criteria to diagnose COPD might have led to inclusion of patients without chronic airflow obstruction in the study. We were unable to assess other factors, previously shown to influence mortality such as poor nutritional status, serum albumin.5,17 presence of corpulmonale or cardiovascular dysfunction.6,11,23,29,30 or impaired renal function. ${ }^{11,23,31}$

\section{REFERENCES}

1. Chok Limsuwat, Nopakoon Nantsupawat, Elvira Umyarova, et al.; Factors affecting mortality in patients with COPD exacerbations requiring ICU admission. The Southwest Respiratory and Critical Care Chronicles 2013;1(2).

2. Kumar S, Khilnani GC, Banga A, et al. Predictors of requirement of mechanical ventilation in patients with chronic obstructive pulmonary disease with acute respiratory failure. Lung India.

2013 Jul-Sep; 30(3):178-182.

3. Archibald R, Chalmers J, Fardon T, et al. Prediction of InHospital Mortality in Acute Exacerbations of COPD; Scottish Universities Medical Journal. 2012;1(2): p.129-139. 
4. Uegan I, et al.: Predictors of hospital outcome and intubation in COPD patients admitted to the respiratory ICU for acute hypercapnic respiratory failure. Respiratory medicine: 2006 January;100(1):66-74.

5. Ai-Ping C, Lee KH, Lim TK, et al. In-hospital and five year mortality of patients treated in ICU for acute exacerbation of COPD: A retrospective study. Chest: 2005 August;128(2):518-524.

6. Raurich JM, et al. In-hospital and two year survival of patients treated with mechanical ventilation for acute exacerbation of COPD; Archives of Broncho pneumonology: 2004 July;40(7):295-301.

7. Afeesa B, Morales IJ, Scanlon PD, et al. Prognostic factors, clinical course and hospital outcome of patients with COPD admitted to an ICU for respiratory failure; Critical care medicine: 2002 July;30(7):1610-1615.

8. American Thoracic Society (ATS): Standards for diagnosis and care of patients with COPD and asthma; American journal of respiratory and critical care medicine: Vol:152, page:S77-S120, 1995.

9. Davidson AC: Pulmonary physician in critical care 11. Critical care management of respiratory failure resulting from COPD. Thorax 2002;57:1079-1084.

10. Chawla GC, Suri JC, Ramakrishnan N, et al. Guidelines for non-invasive ventilation in acute respiratory failure. Indian journal of critical care medicine: 2006;10(2):117128.

11. Martin J Wildman, David A Harrison, Anthony R Brady: Case mix and outcomes for admissions to UK adult CCUs with COPD: a secondary analysis of the ICNARC case mix programme data base. Critical care: 2005;9(suppl 3):S38-S48.

12. Hoo GW, Hakiman N, Santiago SM - Hypercapnic respiratory failure in COPD patients: Response to therapy; Chest: 2000 January;117(1):169-177.

13. Brochard L, Moncebo J, Wysoeki M, et al. - Non-invasive ventilation for acute exacerbation of COPD; New England journal of medicine: 1995;333:817-822.

14. Moretti C, Cilione, Tampieni A, et al. Incidence and causes of Non-invasive mechanical ventilation failure after initial success. Thorax: 2000;55:819-825.

15. British thoracic society standards of care subcommittee: Non-invasive ventilation in acute respiratory failure; Thorax: 2002;57:192-211.

16. Conti V, Terzano C, Mollica C, et al. (2014) Predictors of outcome in COPD patients with hypercapnic respiratory failure requiring NIV; Enliven: J Anesthesiol Crit Care Med 2014;1(1):004.

17. Epstein and Nevins: Predictors of outcome for patients with COPD requiring mechanical ventilation; Chest: 2001;119:1840-1849.
18. Groenwagen, Annenie Schols, Emiel Wonters: Mortality and mortality-related factors after hospitalisation for acute exacerbation of COPD; Chest: 2003;124:459-467.

19. Breene D, Churches T, Hawker F, et al.: Acute respiratory failure secondary to COPD treated in ICU; a long-term follow-up study; Thorax: 2002 Jan;57(1):29-33.

20. Hsu CW, Wann SR, Chiang HT, et al. Comparison of the APACHE II and APACHE III scoring systems in patients with respiratory failure in a medical ICU; J Formos Med Assoc 2001 July;100(7):437-442.

21. Seneff MG, Wagner DP, Wagner RP, et al.: Hospital outcome and 1-year survival of patients admitted to ICU with acute exacerbation of COPD; Critical care medicine: 2002;30:1610-1615.

22. Sudarshan TD, Jeyaseelan L, Thomas K, et al. Predictors of mortality in mechanically ventilated patients; Postgraduate medical journal: 2005;81:780-783.

23. Aran Singanayagam, Stuart Schembri, and James D. Chalmers "Predictors of mortality in hospitalized adults with acute exacerbation of chronic obstructive pulmonary disease. A systematic review and metaanalysis." Annals of the American Thoracic Society, Vol 10, No. 2 (2013); pp. 81-89.

24. Edwards L, Perrin K, Wijesinghe $M$, Weatherall $M$, Beasley R and Travers J (2011). The value of the CRB65 score to predict mortality in exacerbations of COPD requiring hospital admission. Respirology, 16:625-629.

25. Shorr AF, Sun X, Johannes RS, et al. Validation of a novel risk score for severity of illness in acute exacerbations of COPD.

Chest 2011;140(5):1177-1183.

26. Lim WS, Van Der Eerden MM, Laing R, et al. (2003) "Defining community acquired pneumonia severity on presentation to hospital: an international derivation and validation study." Thorax 58(5):377-82.

27. Yang S, Devanand, Tan KL, et al. Acute exacerbation of COPD requiring admission to ICU; Respirology: 2004 Nov;9(4):543-549.

28. Simmonds AK - Ethics and decision making in end-stage lung disease; Thorax: 2003;58:272-277.

29. John M Luce. "End-of-life decision making in the intensive care unit." American Journal of Respiratory and Critical Care Medicine. Vol. 182, No. 1 (2010), pp. 6-11.

30. Terzano C1, Conti V, Di Stefano F, et al. Comorbidity, hospitalization and mortality in COPD: results from a longitudinal study; Lung 2010 Aug;188(4):321-9.

31. Alex C Asiimwe, Fraser JH Brims, Neil P Andrews, Dave R Prytherch, Bernie R Higgins, Sally A Kilbur, et al. Routine laboratory tests can predict In-hospital mortality in acute exacerbations of COPD Lung; June 2011; Volume 189, Issue 3, pp 225-232. 